\title{
THERMAL LENSING IN HIGH-POWER DIODE-PUMPED Yb:KGW LASER
}

\author{
D. Stučinskas, R. Antipenkov, and A. Varanavičius \\ Deptartment of Quantum Electronics, Faculty of Physics, Vilnius University, Sauletekio 9 bldg. 3, LT-10222 Vilnius, \\ Lithuania \\ E-mail: darius.stucinskas@ff.vu.lt
}

Received 25 August 2009; revised 4 May 2010; accepted 17 June 2010

\begin{abstract}
We investigated thermal-lensing effects in a diode end-pumped $\mathrm{Yb}: \mathrm{KGW}$ laser with slab shaped active element. Performance and thermal lensing properties for $N_{\mathrm{g}}$ cut $\mathrm{Yb}: \mathrm{KGW}$ and $\mathrm{Yb}: \mathrm{KGW}$ cut for athermal propagation direction are presented. It is found that crystal cut along athermal direction provides weaker thermal lens than $N_{\mathrm{g}}$ cut active element, however, due to anisotropic Yb:KGW characteristics, thermal lens is highly astigmatic. End bulging contribution to thermal lensing under intense pump was measured (for $N_{\mathrm{g}}$ cut active element).
\end{abstract}

Keywords: Yb:KGW, thermal lens, diode-pumped, athermal orientation

PACS: 42.55.Xi, 42.60.By

\section{Introduction}

Femtosecond laser sources became promising tool for various scientific and industrial applications. High average power and repetition rates are required to speed up operation processes. Relatively broad spectral amplification bandwidth of $\mathrm{Yb}$ in crystalline hosts, along with small quantum defect, allows design of efficient, high average power femtosecond lasers, using direct diode pumping [1]. During the last decade, research committed to $\mathrm{Yb}^{3+}$ doped laser crystals like YAG, $\mathrm{YVO}_{4}, \mathrm{KGd}\left[\mathrm{WO}_{4}\right]_{2}(\mathrm{KGW})$, and $\mathrm{KY}\left[\mathrm{WO}_{4}\right]_{2}(\mathrm{KYW})$ for the development of high power ultrashort pulse lasers has been performed [1-3]. Yb:KGW exhibits an attractive set of parameters which makes it as one of the best choices for lasers operating around $1 \mu \mathrm{m}$. Small quantum defect together with absence of upconversion and excited state absorption gives high slope efficiencies [4]. Intrinsic $\mathrm{Yb}: \mathrm{KGW}$ birefringence allows for low intracavity losses caused by thermally induced birefringence. The broad gain bandwidth obtainable in these crystals makes available the femtosecond pulse generation. Another attractive feature seems to be the existence of athermal crystal cut direction that helps to reduce the thermal lens in an active element of a laser [5]. Although thermal conductivity in $\mathrm{Yb}: \mathrm{KGW}$ is about three times lower than in Yb:YAG, it is, however, significantly higher as compared to $\mathrm{Yb}$ :glass, making the use of $\mathrm{Yb}: \mathrm{KGW}$ quite promising for the femtosecond pulse average power scaling. Average output power levels of $\sim 130 \mathrm{~W}$ using femtosecond fibre lasers was demonstrated [6]. The main drawback of fibre laser design is a small aperture of fibre core that limits the maximum pulse energy to some $100 \mu \mathrm{J}$ [7]. The possibility to achieve high doping levels makes $\mathrm{Yb}: \mathrm{KGW}$ attractive for thin disk laser applications. It has been demonstrated that thin disk lasers are well suitable for sub-200 fs pulses in $500 \mu \mathrm{J}$ energy range [8]. Such systems can be easily scaled to $1 \mathrm{~mJ}$ range. However, such designs tend to be quite complex due to multiple passes through a short active element limiting in this way the use of such lasers in industrial applications. End-pumping schemes offer in most cases more compact and less expensive laser designs. Highest slope efficiencies have been reported for end-pumped configurations [2]. To our knowledge, highest average output powers up to date are demonstrated with commercial chirped pulse amplification systems Pharos [9] and FemtoRegen [10], with output powers up to $10 \mathrm{~W}$ and pulse energies of $\sim 1 \mathrm{~mJ}$ at repetition rates of $1 \mathrm{kHz}$. With some exceptions, such as in [11], many of the $\mathrm{Yb}: \mathrm{KGW}$ crystals in laser systems have been cut for propagation along the $b$ crystallographic direction $(b$ cut), which is parallel to $N_{\mathrm{p}}$, giving access to the largest absorption and emission cross-sections. Thermal lens measurements in $c$ cut 5 at. \%-doped $\mathrm{Yb}: \mathrm{KGW}$ have 

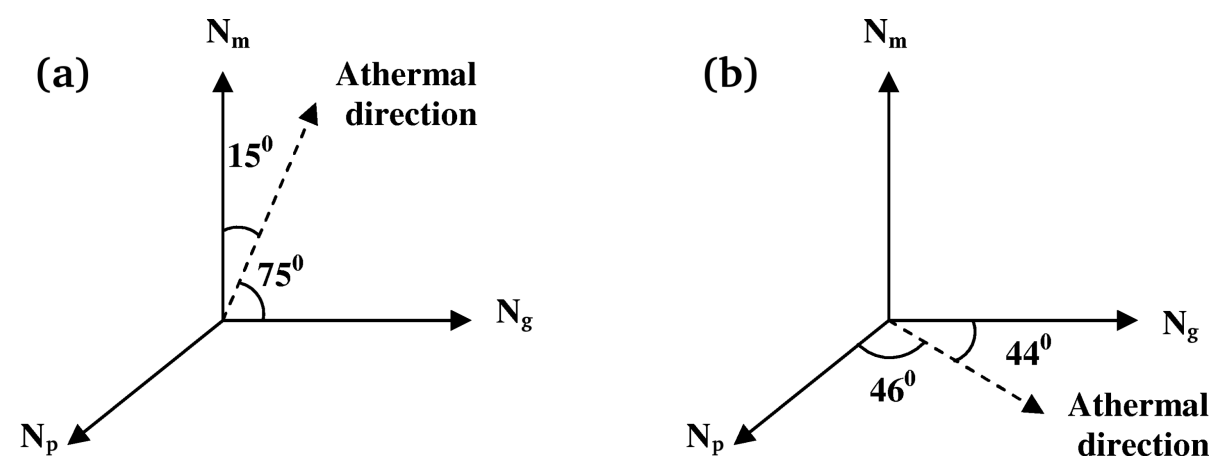

Fig. 1. (a) Athermal direction of propagation relative to the principle axes for KGW in the m-g plane for $E \|$ p. (b) Athermal direction of propagation in the p-g plane for $E \| \mathrm{m}$. Adapted from [12].

been performed at relatively low absorbed powers in [11]. Unfortunately, data regarding the thermally induced astigmatism have not been reported there. However, based on recent measurements of thermo-optic coefficients and thermal expansion using a homogeneous heating, Biswal et al. $[12,13]$ proposed possible athermal propagation directions, where the thermooptic and thermal expansion effects approximately cancel each other. One of the proposed directions for the light polarized along the $N_{\mathrm{p}}$ axis is in the m-g plane, $15^{\circ}$ clockwise from the optical axis $N_{\mathrm{m}}[12,13]$. This athermal direction was investigated by Hellstrom et al. [5]. Another athermal orientation of interest is for $E \| \mathrm{m}$ because the emission and absorption cross-sections for this polarization are significantly higher in $\mathrm{Yb}: \mathrm{KGW}$. The athermal direction of propagation is located $\pm 46^{\circ}$ from the $\mathrm{p}$ axis in the $\mathrm{p}-\mathrm{g}$ plane as shown in Fig. 1(b) [12].

The goal of this work is to investigate and compare properties of the thermal lensing and thermal beam distortions in high-power laser diode end-pumped $\mathrm{Yb}$ : $\mathrm{KGW}$ crystals cut for beam propagation along the $N_{\mathrm{g}}$ axis and along the athermal direction in the $N_{\mathrm{p}}-N_{\mathrm{g}}$ plane.

\section{Experiment}

Two types of Yb:KGW crystal were used: the first was cut for light propagation along the $N_{\mathrm{g}}$ crystallographic direction (see Fig. 2(a)) [14] and the second was cut for propagation along athermal orientation (see Fig. 2(b)) [12]. We have used $5 \mathrm{~mm}$ length, $6 \times 1.2 \mathrm{~mm}^{2}$ aperture and 1.6 at. \%-doped active elements pumped by two high brightness, polarization preserving laser diode pump modules of $50 \mathrm{~W}$ maximum optical output power at $980 \mathrm{~nm}$ wavelength, produced by Light Conversion Ltd., and ensuring pump intensity on the crystal up to $70 \mathrm{~kW} / \mathrm{cm}^{2}$. Crystal orientation and orientation of thermal expansion axes [12-14] in relation to laser beam propagation is shown in Fig. 2.

The schematic diagram of experimental set-up that employs slab shaped $\mathrm{Yb}: \mathrm{KGW}$ active element is presented in Fig. 3. Resonator consists of a flat mirror $M 3$ (reflectivity $R=100 \%$ ) and spherical mirrors $M l$ and $M 2$ (radius $r=-300 \mathrm{~mm}, R=100 \%$ ). Other components are $\lambda / 4$ phase plate $F P$ and a pair of the thin-film polarizers $P$. The polarization plane of pump radiation in all the cases was parallel to $N_{\mathrm{m}}$ optical axis.

We employed a Shack-Hartmann wavefront sensor for measurement of the phase distortions acquired by probe beam of He-Ne laser after passing of pumped laser crystal (see experimental set-up presented in Fig. 3). Probe beam polarization was orientated to match laser's polarization. The Shack-Hartmann wavefront sensor was built using a $40 \times 40$ lenslet array with lenslet size of $108 \mu \mathrm{m}$ and Dalsa 1M15 CCD camera. In order to match the dimensions of pumped region in laser crystal and lenslet array we used a magnifying 4F imaging lens system (lenses $L 1$ and $L 2$ in Fig. 3). Additional mirror $M 4$ (anti reflective coated for lasing wavelength $1030 \mathrm{~nm}$ and high reflective for $632 \mathrm{~nm}$ probe beam) was used to pick up the probe beam from laser cavity. Such set-up allows measurements of thermal lens in both lasing (with laser oscillation) and non-lasing conditions (with laser cavity blocked).

\section{Thermal lensing in $N_{\mathrm{g}}$ cut $\mathrm{Yb}$ :KGW active element}

At the first stage of experiments we examined $N_{\mathrm{g}}$ cut active element. Thermal lens measurements were carried out at various pump powers for lasing and nonlasing conditions. Typical probe beam wavefront distortion after passing the thermal lens in $N_{\mathrm{g}}$ cut active element at highest pump power (lasing conditions) is presented in Fig. 4. 

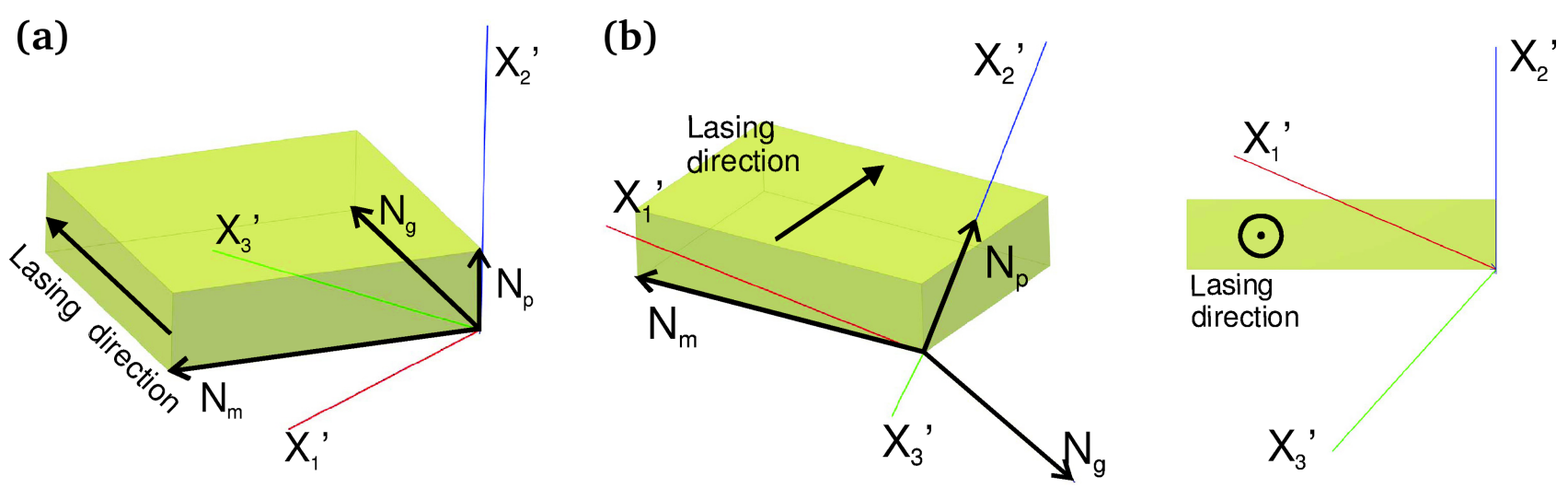

Fig. 2. (a) $N_{\mathrm{g}}$ cut crystal orientation in relation to direction of propagation. Thermal expansion axes $X_{1}^{\prime}$ and $X_{3}^{\prime}$ are in $N_{\mathrm{m}}-N_{\mathrm{g}}$ plane, $X_{2}^{\prime}$ is orientated along $N_{\mathrm{p}}$ axis. (b) Athermal direction cut crystal orientation in relation to direction of propagation. Thermal expansion axes $X_{1}^{\prime}$ and $X_{3}^{\prime}$ are in $N_{\mathrm{m}}-N_{\mathrm{g}}$ plane.
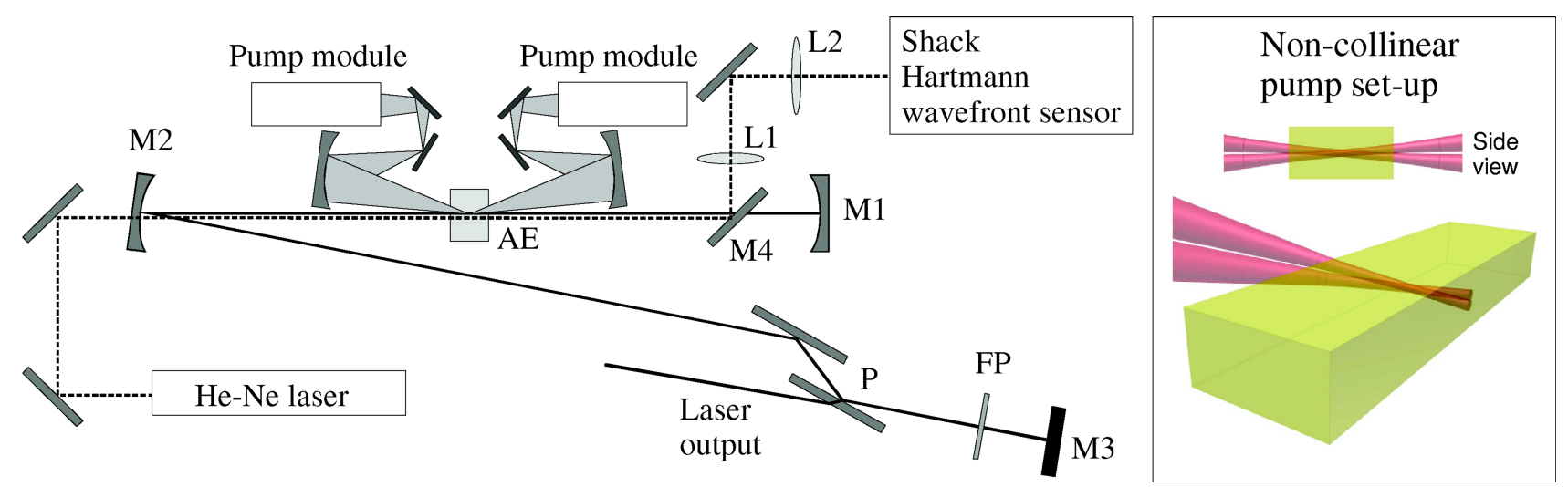

Fig. 3. Experimental set-up. Pump set-up of the laser active element is shown on the right. Note that non-collinear arrangement of pump beams results in an oval shaped pump distribution at active element's facet.
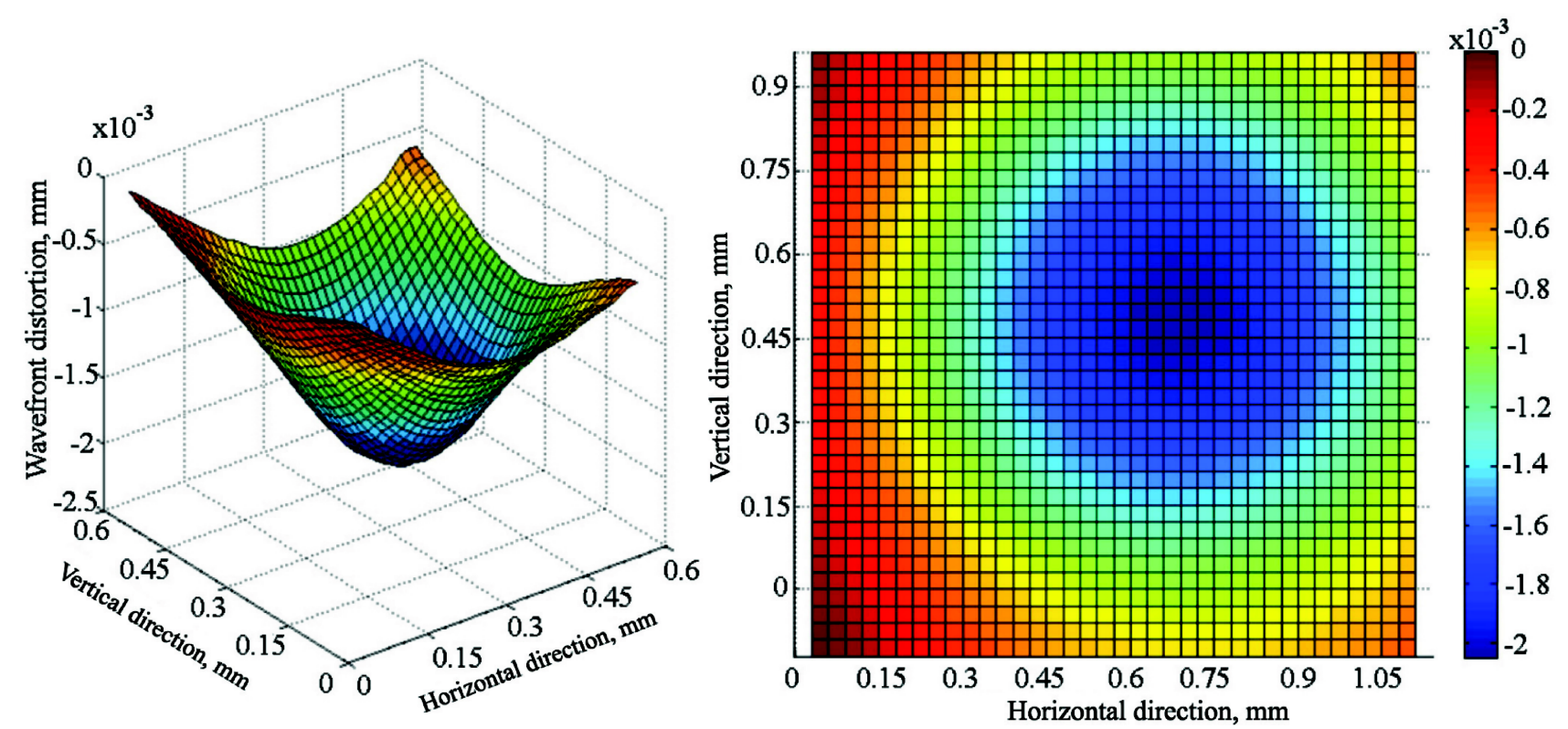

Fig. 4. Measured probe beam wavefront distortion after passing thermal lens in $c$ cut active element at $94 \mathrm{~W}$ pump power (lasing conditions). 


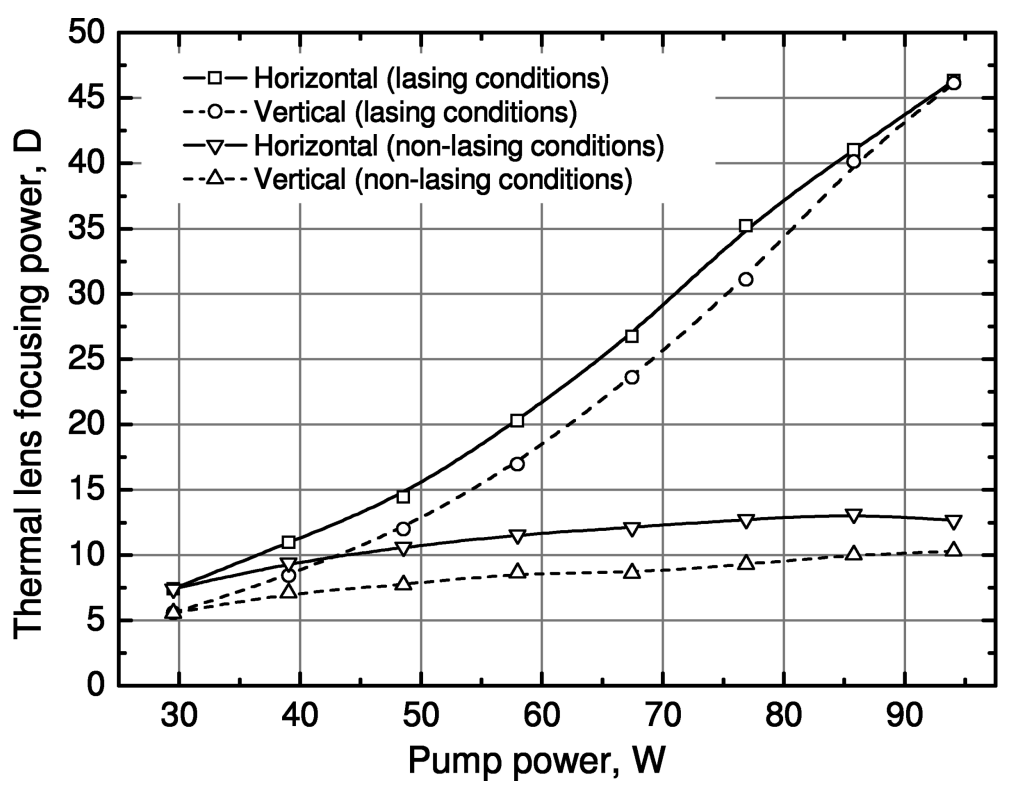

Fig. 5. Thermal lens focusing power for vertical and horizontal directions in lasing and non-lasing conditions at different pump powers.

Variation of the thermally induced lens maximum focusing power calculated from data of wavefront distortion measurements versus the total pump power is presented in Fig. 5. These results show that the thermal lens focusing power differs up to 4 times in lasing and non-lasing conditions at highest pump power. Such thermal lens behaviour can be explained assuming that the average fluorescence wavelength in this material is $993 \mathrm{~nm}$. Thus, the quantum defect with laser oscillation at $1030 \mathrm{~nm}$ is higher in lasing condition than without laser oscillation. Such thermal lens influence on laser performance corresponds well to published data of $\mathrm{Yb}: \mathrm{KGW}$ thermal lens measurements [11]. In lasing conditions, as shown in Fig. 5, at low pump powers the thermal lens is astigmatic the focusing power ratio between horizontal and vertical components is 1.4 (stronger in vertical direction). As pump power increases, the focusing power ratio drops, eventually reaching 1 (symmetrical thermal lens) when pump power reaches maximum (94 W). In nonlasing conditions the thermal lens remains astigmatic (stronger in vertical direction) even at highest available pump powers. Such thermal lens behaviour can be explained assuming non-symmetrical cooling geometry of slab shaped active element and thermal properties of active element: its thermal expansion coefficient for $X_{1}^{\prime}$ axis is $\sim 2.6$ times larger than along $X_{2}^{\prime}$ axis which is orientated vertically [12].

Laser output beam profile was measured using a $\mathrm{CCD}$ camera at the distance of $1 \mathrm{~m}$ from a laser output mirror (see Fig. 6). The main criteria for cavity adjustment were symmetrical TEM 00 output beam profile and output power. By adjusting cavity end mirrors and pump position it is possible to maintain a symmetrical laser output up to $\sim 80 \mathrm{~W}$ of pump power. Increasing the pump power above $80 \mathrm{~W}$ results in a gradual raise of distortions of beam's profile and the beam cross-section transforms into the elliptical one. However, as seen in figure, distribution remains nearly Gaussian in traverse directions. At first, it might be surprising that for a symmetrical thermal lens the laser output beam becomes non-symmetrical. We attribute such behaviour to non-symmetrical arrangement of pump beams (see Fig. 3) that results in a slightly asymmetric pump channel whose cross-section ellipticity increases towards crystal faces. When the laser output power is low, the spatial gain profile in $\mathrm{Yb}: \mathrm{KGW}$ crystal is determined essentially by the symmetric Gaussian mode of the cavity. As pump increases, an absorption saturation in active element volume defined by cavity mode is eventually reached and a larger pump portion absorbed in peripheral pump channel area leads to a perturbation of symmetric gain profile.

\section{End bulging of active element under thermal load}

Heat deposition in end-pumped lasers is very inhomogeneous. A much localized heat deposition leads to highly non-uniform and complex temperature and stress profiles. Besides the temperature and stress dependent variations of the refractive index, the contribution of active element end surface bulging to the formation of a thermal lens can be substantial in end-pumped 


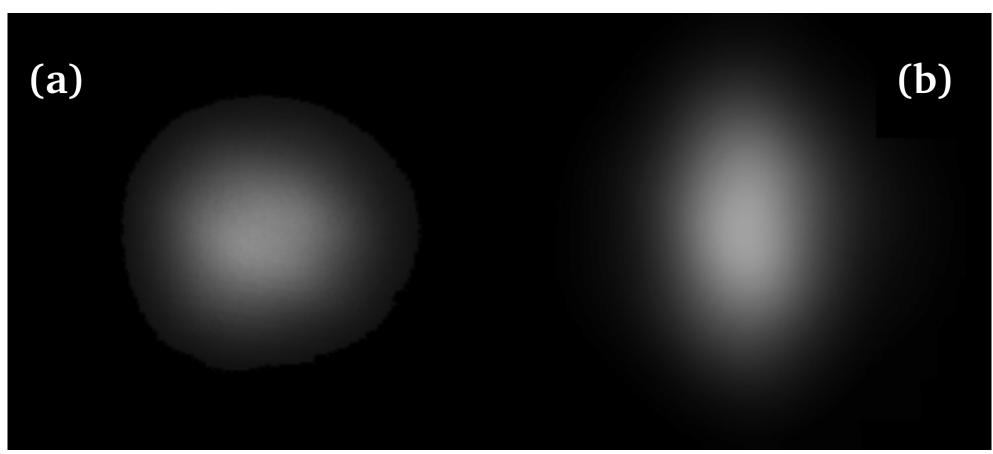

Fig. 6. Laser output beam profile at different values of laser output power when laser pump power is (a) $77 \mathrm{~W}$ and (b) $86 \mathrm{~W}$.

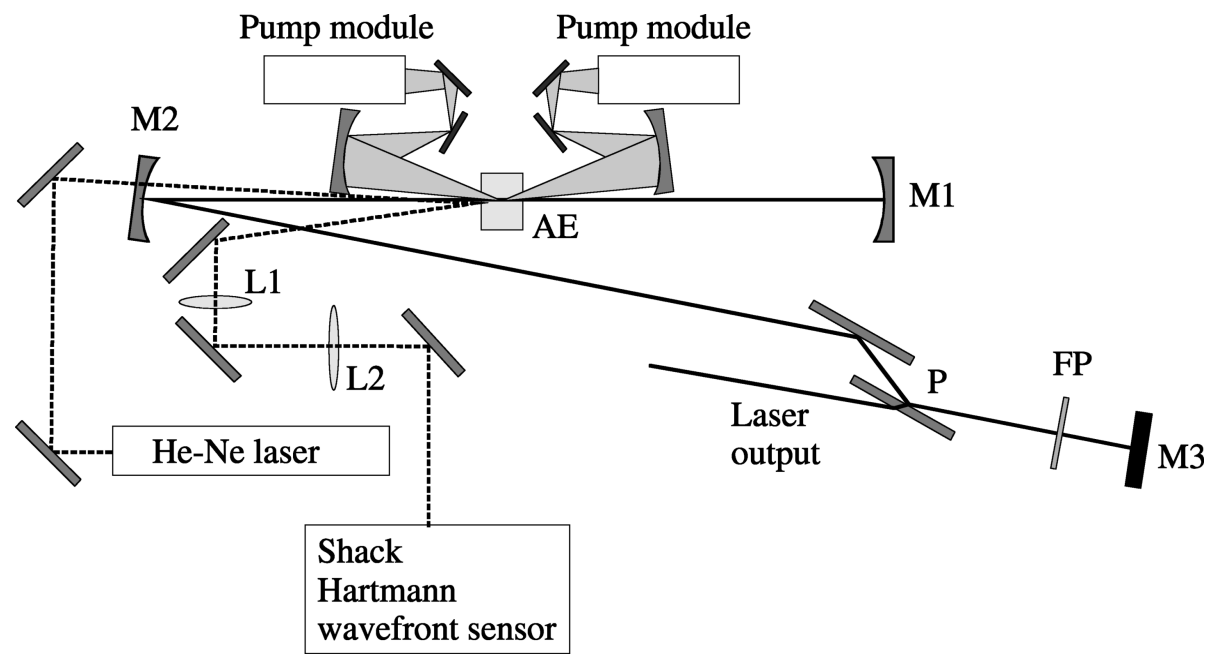

Fig. 7. Experimental set-up for end-bulging measurements.

lasers and has been reported to be as high as $\sim 35 \%$ for Nd:YAG [15] and up to 50\% for Nd:YLF [16] and $\mathrm{Nd}: \mathrm{YVO}_{4}[17]$. Whereas, in $\mathrm{Yb}: \mathrm{KGW}$ crystals the end bulging measurements, to our knowledge, have not been reported.

Experimental set-up was modified for measurements of end bulging (see Fig. 7). Probe beam was directed at active element's facet at a small angle of incidence. Thermal lens was calculated from reflected probe beam wavefront distortions. In our case the active element is pumped from both sides, therefore we consider that the end bulging in both ends of crystal is equal. Measurements were performed with crystal cut for beam propagation along the $N_{\mathrm{g}}$ axis. Measured crystal facet deformations were used to calculate the thermal lens focal length contributed by the end bulging. For calculations we employed a thick lens formula.

Contribution of end bulging expressed as the fraction of thermal lens is presented in Fig. 8. The end bulging has more influence to thermal lens in horizontal rather than vertical direction. This contributes to the thermal lens astigmatism (see Fig. 5). As seen in Fig. 8, in vertical direction the end bulging contributes to total ther- mal lens by $\sim 10 \%$ in a wide range of pump powers (in both lasing and non-lasing conditions). In horizontal direction, the end bulging contributes up to $50 \%$ of total thermal lens in non-lasing conditions and $\sim 20 \%$ at high pump powers in lasing conditions.

Crystal facet thermal deformations highly depend on the pump set-up. In our case, the laser active element is pumped from by two pump modules, from opposite ends. Pump is slightly non-collinear in order to protect the pump modules from damaging each other. This causes a non-symmetrical (in lasing beam perspective) thermal distribution, which (along with non-symmetric cooling geometry) in its turn results in a non-symmetrical thermal lens. Such thermal lens behaviour can be explained assuming some Yb:KGW thermal properties: in non-lasing conditions, most heating occurs in the pump channel (where pump is absorbed), while in lasing conditions, heating occurs in cavity mode in the active element volume (higher output power results in more pump absorbed in cavity mode volume, therefore more heating). The thermal lens component dependent on stress and $\mathrm{d} n / \mathrm{d} T$ is stronger in vertical direction, meanwhile the end 


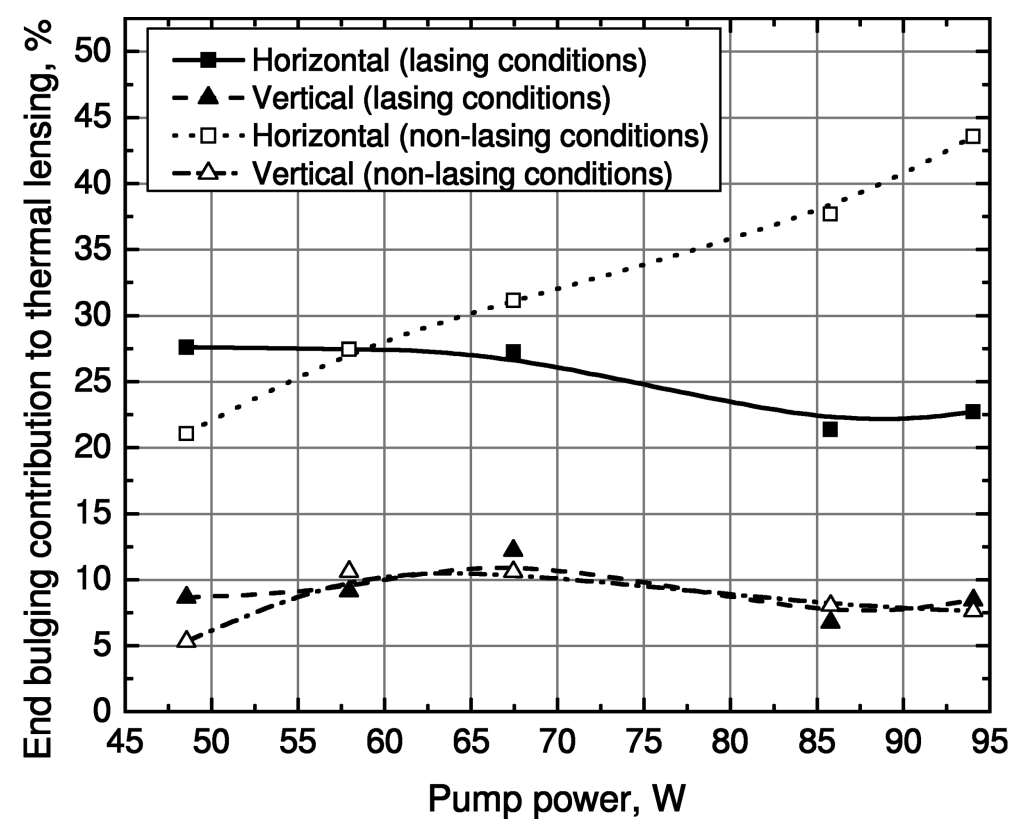

Fig. 8. Contribution of end bulging expressed as the fraction of total thermal lens for vertical and horizontal directions in lasing and non-lasing conditions at different pump powers.

bulging component is stronger in horizontal direction, due to pump geometry. By changing the pump intersection angle it is possible to control the astigmatism of total thermal lens. The impact of pump shaping to thermal lensing has been reported by Hoos et al. [18].

\section{Thermal lensing in athermal Yb:KGW active element}

Next step of experiments was the examination of thermal lens in active element and laser operation when using $\mathrm{Yb}: \mathrm{KGW}$ crystal cut along an athermal direction. Crystal orientation and orientation of thermal expansion axes in relation to laser beam propagation is shown in Fig. 2(b). Thermal lens measurements were carried out at various pump powers for lasing and non-lasing conditions. Typical probe beam wavefront distortion after passing thermal lens in athermal cut active element at highest pump power (lasing conditions) is presented in Fig. 9.

In contrast to the case of $N_{\mathrm{g}}$ cut $\mathrm{Yb}: \mathrm{KGW}$, the wavefront distortions form a pattern which has an elliptical shape and is tilted with reference to vertical direction by $\sim 40^{\circ}$. Thus, the thermal lens in athermal active element is highly astigmatic. The major axis of ellipse is called the slow axis, and the minor axis the fast axis. We believe that such behaviour is determined by highly anisotropic $\mathrm{Yb}: \mathrm{KGW}$ properties. In the case of uniform heating, this crystal might exhibit athermal behaviour in particular directions, however, in our case the active element is heated locally in comparatively small volume. Due to thermal gradients, thermal expansion of active element results in a stress induced thermal lens. We found that the fast axis of thermal lens is orientated closely to the thermal expansion axis $X_{3}^{\prime}$. The active element was flipped (along horizontal axis) in order to find out if such thermal lens behaviour results from the active element physical properties or a misalignment of the pump. When the active element was flipped over, the tilt of elliptical wavefront distortion pattern flipped as well forming a mirror image of the pattern shown in Fig. 9. This confirmed that the non-symmetrical nature of thermal lens is caused by physical properties of the active element. Similar thermal lens was observed for 3 different concentrations, same orientation active elements, with comparable results. The variation of thermally induced lens maximum focusing power was calculated from the data on wavefront distortion measurements and is presented in Fig. 10.

As shown in Fig. 10, under lasing conditions the thermal lens focusing power differs up to 3 times for fast and slow axes of thermal lens. Compared to $N_{\mathrm{g}}$ cut active element performance (see Fig. 5) at highest available pump, the thermal lens in athermal cut active element is smaller by $30 \%$ for fast axis and $80 \%$ for slow axis.

Laser output beam profiles at different values of pump power are shown in Fig. 11. For pump powers above $\sim 40 \mathrm{~W}$ the laser output beam profile becomes elliptical, with major axis offset anticlockwise from vertical by nearly $40^{\circ}$. Such thermal lens behaviour 

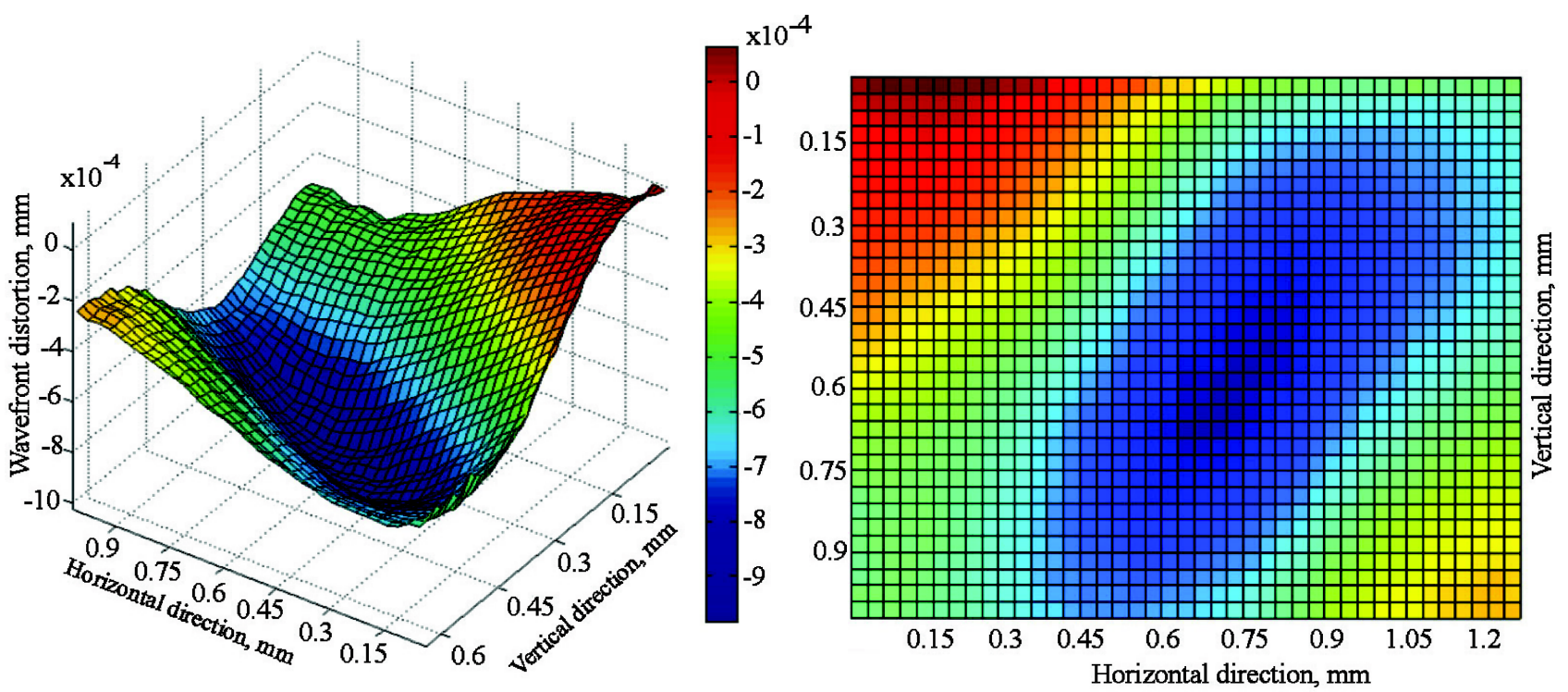

Fig. 9. Measured probe beam wavefront distortion after passing thermal lens in athermal orientation active element at $96 \mathrm{~W}$ pump power (lasing conditions).

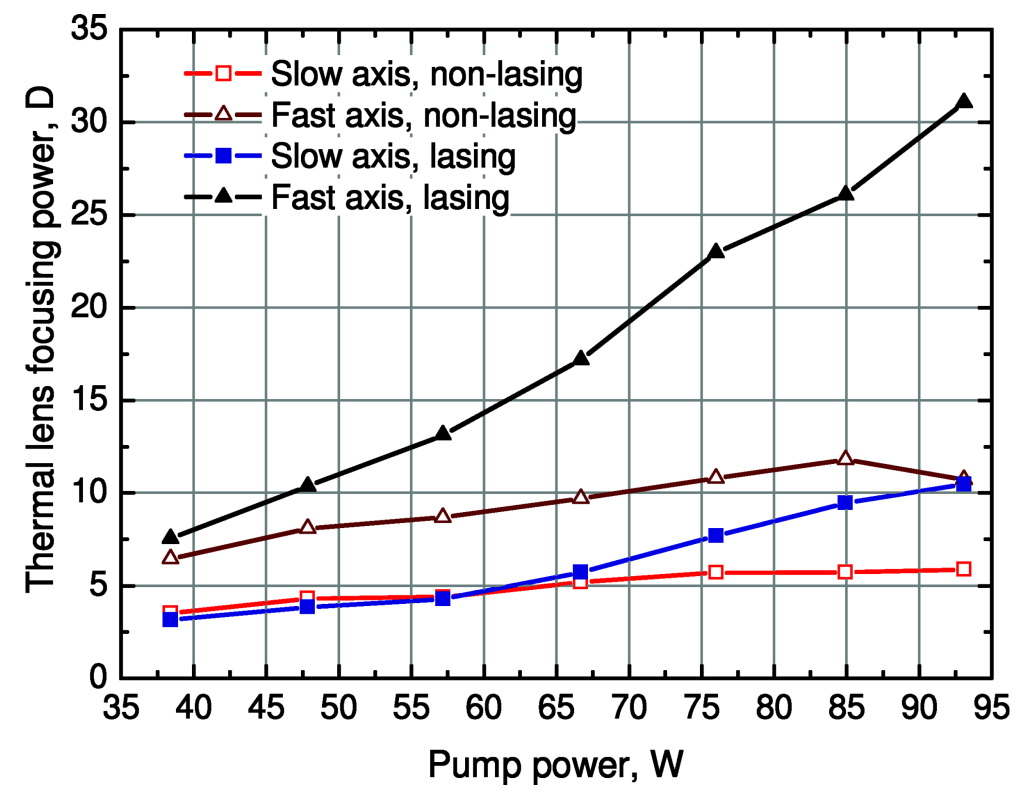

Fig. 10. Thermal lens focusing power in lasing and non-lasing conditions at different pump powers.

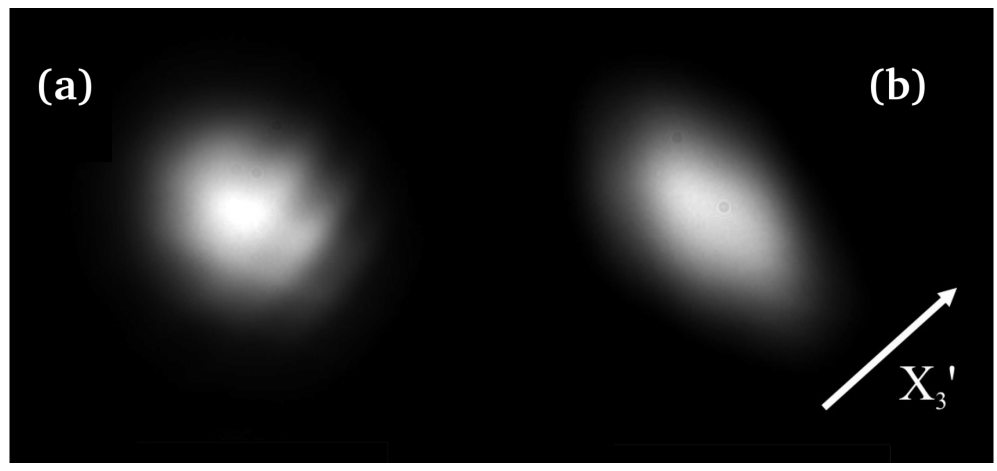

Fig. 11. Laser output beam profile at different values of laser output power when laser pump power is (a) $39 \mathrm{~W}$ and (b) $86 \mathrm{~W}$ (with projection of $X_{3}^{\prime}$ thermal expansion axis). 


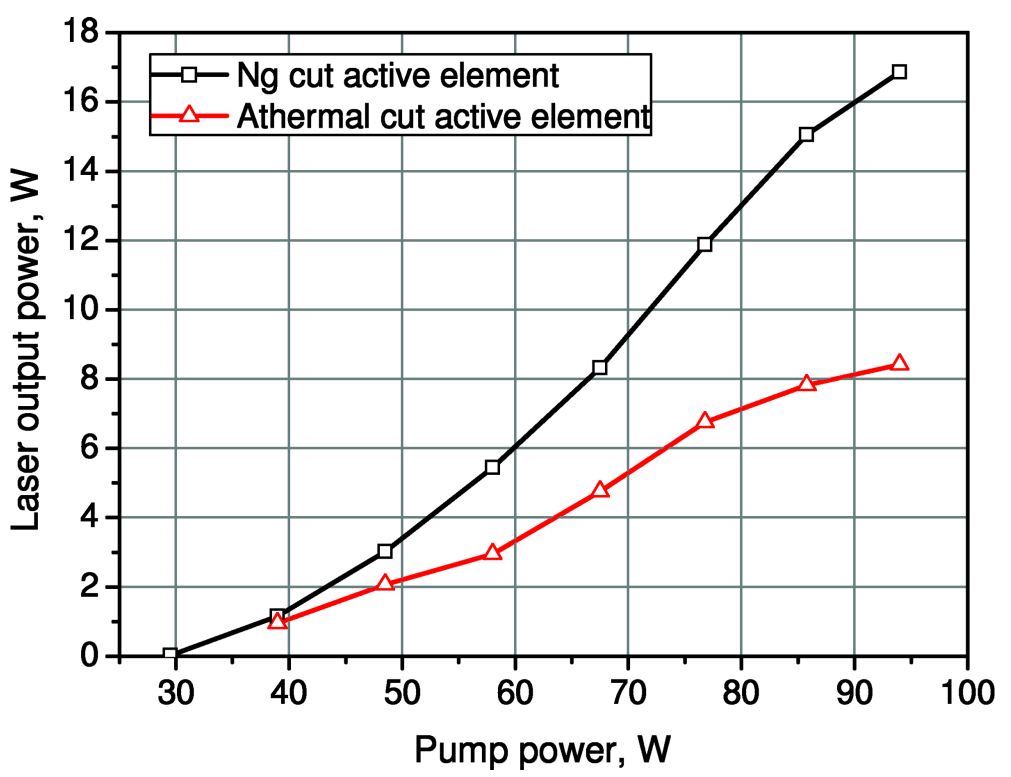

Fig. 12. Measured laser output power dependence on pump power in $\mathrm{CW}$ mode operation (for $N_{\mathrm{g}}$ cut and athermal cut active elements).

results from the orientation of thermal expansion axes (projection of $X_{3}^{\prime}$ thermal expansion axis is shown in Fig. 2(b)).

The measured laser output power dependence on pump power in CW mode operation is shown in Fig. 12. Notably the laser output power is 2 times smaller when using the athermal cut $\mathrm{Yb}: \mathrm{KGW}$ crystal compared to the $N_{\mathrm{g}}$ cut active element.

\section{Conclusions}

We have presented experimental values of the focal length of thermal lenses in end-pumped $N_{\mathrm{g}}$ cut $\mathrm{Yb}: \mathrm{KGW}$ active element. The contribution of active element end bulging to the total thermal lens focusing power has been examined as well. Yb:KGW active element cut for propagation along athermal direction proposed by Biswal et al. [12], has been tested under both lasing and non-lasing conditions.

A maximum output power of $8.5 \mathrm{~W}$ for $94 \mathrm{~W}$ of pump power was achieved with the athermal direction cut crystal. For comparison, the $N_{\mathrm{g}}$ cut crystal generated almost $17 \mathrm{~W}$ of output power for the same incident pump power. The thermal lens in both the $N_{\mathrm{g}}$ cut and the athermal direction cut crystals is determined primarily by the anisotropic thermal expansion of the $\mathrm{Yb}: \mathrm{KGW}$. Thermal gradients due to pump beam geometry cause a thermal lens even in the athermal direction cut configuration. The tests confirmed that the thermal lens is lower than in conventional $N_{\mathrm{g}}$ cut $\mathrm{Yb}: \mathrm{KGW}$. However, the laser beam for the investigated athermal cut is characterized by a much higher astigmatism than for the $N_{\mathrm{g}}$ cut active element. Moreover, the fast axis of thermal lens is offset by $40^{\circ}$ from vertical, further complicating the use of such crystals. Considering higher efficiency and more symmetric thermal lens, the $N_{\mathrm{g}}$ cut $\mathrm{Yb}: \mathrm{KGW}$ is better suited for applications in high average power femtosecond laser systems than the investigated athermal direction of propagation.

\section{References}

[1] W.F. Krupke, Ytterbium solid-state lasers - the first decade, IEEE J. Sel. Topics Quantum Electron. 6(6), 1287-1296 (2000).

[2] J.H. Hellström, S. Bjurshagen, V. Pasiskevicius, J. Liu, V. Petrov, and U. Griebner, Efficient Yb:KGW lasers end-pumped by high-power diode bars, Appl. Phys. B 83, 235-239 (2006).

[3] G.R. Holtom, Mode-locked Yb:KGW laser longitudinally pumped by poliarization-coupled diode bars, Opt. Lett. 31, 2719-2721 (2006).

[4] W.F. Krukpe, New laser materials for diode pumped solid state lasers, Curr. Opin. Solid State Mater. Sci. 4(2), 197-201 (1999).

[5] J.H. Hellstrom, S. Bjurshagen, and V. Pasiskevicius, Laser performance and thermal lensing in highpower diodepumped $\mathrm{Yb}: \mathrm{KGW}$ with athermal orientation, Appl. Phys. B 83, 55-59 (2006).

[6] F. Röser, J. Rothhard, B. Ortac, A. Liem, O. Schmidt, T. Schreiber, J. Limpert, and A. Tünnermann, $131 \mathrm{~W}$ 220 fs fiber laser system, Opt. Lett. 30, 2754-2756 (2005).

[7] L. Shah, Z. Liu, I. Hartl, G. Imeshev, G.C. Cho, and M.E. Fermann, High energy femtosecond $\mathrm{Yb}$ cubicon fiber amplifier, Opt. Express 13, 4717-4722 (2005). 
[8] U. Buenting, H. Sayinc, D. Wandt, U. Morgner, and D. Kracht, Regenerative thin disk amplifier with combined gain spectra producing $500 \mu \mathrm{J}$ sub 200 fs pulses, Opt. Express 17, 8046-8050 (2009).

[9] http://www.lightcon.com/index.php?id=29,0,0,1,0,0 .

[10] http://www.highqlaser.at/en/products/regenerativeamplifiers/femtoregen-series .

[11] S. Chénais, F. Druon, F. Balembois, G. Lucas-Leclin, and P. Georges, Thermal lensing in diode-pumped ytterbium lasers - part II: Evaluation of quantum efficiencies and thermo-optic coefficients, IEEE J. Quantum Electron. 40(9), 1235-1243 (2004).

[12] S. Biswal, S.P. O'Connor, and S.R. Bowman, Thermooptical parameters measured in ytterbium-doped potassium gadolinium tungstate, Appl. Opt. 44, 3093-3097 (2005).

[13] V.V. Filippov, N.V. Kuleshov, and I.T. Bodnar, Negative thermo-optical coefficients and athermal directions in monoclinic $\mathrm{KGd}\left(\mathrm{WO}_{4}\right)_{2}$ and $\mathrm{KY}\left(\mathrm{WO}_{4}\right)_{2}$ laser host crystals in the visible region, Appl. Phys. B 87(4), 611614 (2007).

[14] M.C. Pujol, X. Mateos, M.A.R. Solé, J. Massons, J. Gavaldà, X. Solans, F. Díaz, and M. Aguiló,
Structure, crystal growth and physical anisotropy of $\mathrm{KYb}\left(\mathrm{WO}_{4}\right)_{2}$, a new laser matrix, J. Appl. Crystallogr. 35, 108-112 (2002).

[15] R. Weber, B. Neuenschwender, M. Macdonald, M.B. Roos, and H.P. Weber, Cooling schemes for longitudinally diode-laser pumped Nd:YAG rods, IEEE J. Quantum Electron. 34, 1046-1053 (1998).

[16] T. Baer, W. Nighan, and M. Keierstead, Modeling of end-pumped, solid-state lasers, in: Conference on Lasers and Electro-optics, 1993 OSA Technical Digest Series, Vol. 11 (Optical Society of America, Washington, DC, 1993) p. 638.

[17] K. Kleine, L. Gonzalez, R. Bhatia, L. Marshall, and D. Matthews, High brightness Nd: $\mathrm{YVO}_{4}$ laser for nonlinear optics, in: Advanced Solid State Lasers, eds. M. Fejer, H. Injeyan, and U. Keller, OSA Trends in Optics and Photonics Series, Vol. 26 (Optical Society of America, Washington, DC, 1999) pp. 157-158.

[18] F. Hoos, S. Li, T.P. Meyrath, B. Braun, and H. Giessen, Thermal lensing in an end-pumped Yb:KGW slab laser with high power single emitter diodes, Opt. Express 16, 6041-6049 (2008).

\title{
ŠILUMINIO LĘŠIO SAVYBĖS DIDELĖS GALIOS DIODINIO KAUPINIMO Yb:KGV LAZERYJE
}

\author{
D. Stučinskas, R. Antipenkov, A. Varanavičius \\ Vilniaus universitetas, Vilnius, Lietuva
}

\section{Santrauka}

Pateikiame eksperimentinius kaupinimo ir lazerinio generavimo indukuoto šiluminio lęšio aktyviajame $\mathrm{Yb}: \mathrm{KGW}$ elemente matavimų rezultatus. Aktyviajame lazerio elemente indukuoto šiluminio lęšio laužiamosios gebos priklausomybė nuo kaupinimo galios buvo nustatyta matuojant zonduojančio pluošto bangos fronto po- kyti Šako (Shack) ir Hartmano (Hartmann) matuokliu. Matavimus atlikome su dviejų skirtingų orientacijų aktyviaisiais elementais: $z \| N_{\mathrm{g}}$ ir atermalinès $\angle z: N_{\mathrm{g}}=44^{\circ}$ orientacijos Yb:KGW kristalais. Taip pat buvo atlikti matavimai siekiant išsiaiškinti aktyviojo elemento galų išsigaubimo įtaką termolęšio laužiamajai gebai $z \| N_{\mathrm{g}}$ orientacijos aktyviuosiuose elementuose. 